\title{
The Imperative of Participatory Leadership on Nation Building Towards Inclusive Growth in Zanzibar: A Critical Review of Modern Practices Building Social Cohesion in The Urban West Region, Zanzibar
}

\author{
Ayoub Mohammed Mahmoud* \\ Open University of Tanzania-Zanzibar Centre, Tanzania \\ *Corresponding author: Ayoub Mohammed Mahmoud, Open University of Tanzania-Zanzibar Centre, P.0 Box 2599, Zanzibar, \\ Tanzania
}

\begin{abstract}
This paper examines the imperative of participatory leadership towards inclusive growth in Zanzibar where a critical review of modern practices towards building social cohesion was undertaken in the Urban West Region, Zanzibar. The study applied both desk-based literature survey and descriptive survey research designs were adopted for the study. Various data collection methods including literature review observation, interviews and questionnaire survey were used to collect information from a total of 60 respondents from the study area. The analysis of the collected qualitative and quantitative data was done through contents analysis and descriptive statistics respectively. Based on the analyzed data the study reveals participatory resource mobilization, community participatory project implementation, community mobilization practices, enhanced community participation and involvement practices and community assurance of peace and harmony as the main available participatory leadership practices in Zanzibar. On the other hand, it was concluded from the study findings, that the contribution of participatory leadership on building social cohesion in Zanzibar include improving community welfare, improving community functional facilities and also participatory leadership enhances transparency and accountability among various actors in the community. Finally, the study concludes citizens, traditional leaders, religious leaders, government leaders and community groups as the main actors in the participatory leadership practices undertaken in the Urban West Region, Zanzibar. Also basing on the study findings, community attitudes were concluded to be the major factor among the revealed factors influencing the participatory leadership practices in the Urban West, Zanzibar. Based on the study findings, the government leaders are urged to deliberately change their leadership style such that involve and engage wider part of the community members as it has been proven to be highly useful in the development process. Also, traditional and religious leaders are hereby urged to equip themselves with the basic understanding of the participatory leadership since it is a useful strategy for joining hands with government leaders in quick and effective community mobilization process. Finally, the citizens who stand as one of the potential actors in the participatory leadership process; should cultivate the culture and mentality for fitting them in the participatory leadership process such that their attitudes can start changing to adapt and fit the participatory leadership practices. Lastly, the study urges government authorities to integrate participatory leadership practices in the curriculum for building up the culture in schools and other formal and informal learning institutions in Zanzibar. This will ensure the sustainable change in attitudes and behaviors towards adoption of participatory leadership practices in their daily participation in the development initiatives..
\end{abstract}

Keywords: Participatory leadership; Nation building; Inclusive growth; Social cohesion

\section{Introduction}

In the every, community of rational people in the world, leadership is vested the prime obligation of transforming all aspects of the particular community. The transformation of communities towards improving their lives has become the main challenge to the economic and social development efforts of developing nations like Zanzibar. This challenge arises from the need to promote the welfare of the people of the rural and urban communities so that they could acquire a better standard of living in their homes and their entire surroundings communities [1].

Innovating new community development interventions has been a veritable tool for mobilizing and integrating people into contributing meaningfully to the growth of their areas in particular and the process of national development in general [1-3]. This awareness has led many communities to commit themselves to 
embark on activities that could transform their local and rural environment into urban and better developed settings. Mahmoud [2] pointed out that the majority of communities have currently employed communal efforts as the mechanism for mobilizing community resources to provide physical improvement and functional facilities in their localities in the social, political and economic aspects of their life. Thus, physical development of a community is an indicator that development has taken place; upon seeing improved health and education infrastructures implies enhanced socio-economic parameters of any community. Having being posited by many literatures, several multi-level authorities in many countries, especially, the developing countries such as Zanzibar including Urban West Region in Zanzibar have embarked on different pragmatic programmes to make better the lots of the citizens at the grassroots, particularly, in the areas of physical development of communities [4,5].

It is undoubted that the rate of economic growth and development of any community is facilitated by the people's recognition of the need for self-help and their readiness to take necessary actions towards achieving the development [2]. It should be noted that every community in Zanzibar and anywhere in the world needs development, especially, in terms of community infrastructure and social amenities $[2,6]$.

This concurs to the really meaning of community development involves joint efforts of both government and communities. However, in Zanzibar, many communities still believe that developmental programmes are sole responsibility of the government in power. On the other hand majority of literatures posit widely that, projects provided solely by the government without involving the people in many communities could not be sustained because there is no commitment on the part of the people. In such an instance, there is no link between sustainability of projects provided by the government and the interest of the people because people are not involved in decision making. Members of the community should have interest in the programme that affects their welfare and participate actively in the identification of their needs, planning, execution of programmes, utilization and evaluations. Thus, participation yields greater interest in sustainability [2,3]. For sustainability of community development programmes in many areas of Africa to be ensured; Mahmoud [2] \& Abiona [3] identified some key elements of programmes sustainability among which include: programme should be people oriented, the need for stability of government and stable policies; transparency and accountability in all sectors; equal access to resources; and effective political system; recognition and involvement of local institutions in development programmes.

The fact that community development is an age-long practice that could be traced to the tradition before the advent of colonial administration in Zanzibar, the traditional community development efforts evolved voluntary routine exercise in which able-bodied, young and old participated in the traditional tasks of clearing roadpaths and compounds for the protection of land and property. However, with the growing complexity of our society, coupled with increase in population and urbanization, with attendant high taste of the people for modern basic and social amenities, community development witnessed a significant leap and become more complex in process, form and scope in recent years, hence calling for more sophisticated means and ways. The rationale and significance of participatory leadership as well as its scope and form witnessed rapid transformation from mere provision of rudimentary tasks to a more complex task of supplementing governments' efforts in the provision of basic and social services [2,3,7].

Some of the community development programmes include rehabilitation of roads, skill acquisition programmes, community education programmes, rehabilitation of social services infrastructures including building classrooms, health centres, community security programmes, among others require collective effort from all actors to bring substantial change $[3,8,9]$. It also involves social services and activities like organization of literacy classes, youth forum, men and women associations, cultural and aesthetic shows by individuals and interest groups within the various communities. The vast majority of the populace is still living, devoid of both basic and social amenities. Coupled with this is the acceptance of the fact that meaningful development can only take place when the people are well mobilized for community action. In a bid to foster sustainable community development at the grassroots, government at all levels over the years have intervened in the sustenance and strengthening of meaningful and pragmatic community development programmes [1].

Nation building is deliberate, keenly directed, focused energetic projection of national culture, and collective action to develop a political and economic system of a country sustainably. Akoto defines nation-building as the conscious and focused application of our people's collective resources, energies, and knowledge to the task of liberating and developing the psychic and physical space that we identify as ours. It involves the development of behaviors, values, language, institutions and physical structures that elucidate our history and culture, concretize and protect the present, and insure the future identity and independence of the nation. From the political perspective, it is in the area of developing and instituting a democratic policy. Nation building thus entails the ability of the nation-state to sustain itself as a sovereign by giving freedom and liberty to its people to use a well laid mechanism or system of leadership recruitment and leave a legacy or culture of smooth succession of power to future generation.

In spite of government efforts to achieve meaningful development at the grassroots, many communities are still in pathetic state of stagnation and neglect. On the part of the government sponsored projects, many community projects were abandoned half-way due to poor logistics and financial constraint, poor planning and management. As a result of this, the community development departments are not stable in a ministry but are tossed from one ministry to the other depending on the wishes and caprices of government in power. Lack of consensus as to the proper place of community development in the governmental machinery formed a larger problem in the low priority accorded to community development. Some problems were noticed to have impeded community development programmes such as lukewarm attitude to maintenance, exodus of people from rural to urban area, 
wrong belief of people that government was capable and should provide all their needs for them, inadequate funding on the part of individual members, problem of illiteracy, communal clashes among others $[10,11]$.

The under-development nature of rural communities in Zanzibar is evident rather than a mere expression. It is observed that many states and local governments are deficient in technological infrastructure or in all the good things of life: electricity supply has degenerated, pipe-borne water supply is non-existent, schools are ill-equipped while other social services have drastically degenerated with many of the hospitals now death centers rather than medical centers while many of the roads are now in deplorable condition. In the absence of community supported projects, the number of beggars along the streets has increased drastically and its attendant general restiveness has become a serious menace to both social and economic development $[2,12,13]$. Corroborating this view, a World Bank report (1995) cited in Ugwu [14] observed the fact that: A large number of people in Zanzibar like many other less developed countries in urban area do not have enough income to meet their needs, about $21 \%$ of the urban population-85 million people were estimated to be living below the poverty line. Their cash income is insufficient to cover minimal standards of food, water, fuel, shelter, medical care and school fees.

Essentially, most people in Zanzibar believe that it is the responsibility of government to provide, maintain and sustain all infrastructures. Despite the term participatory leadership being so rhetorical in these recent times, different people in different contexts use it to connote different things but mostly on changing things in a better manner. In most cases participatory leadership connotes the ability of leader to form and encourage people's participation as identified by Singh cited in Ugwu [14] based on their experience the following are the key issues to put on considerations: Firstly, attending meetings; secondly, contributing resources; thirdly, seeking new knowledge and information and sharing; fourthly, following the rules and regulations set by the community; fifthly, adoption of technologies and practices recommended by the project authority; sixthly, abstaining from doing any harm or damage to the common property; seventhly, serving on the joint management committees constituted by the project authority for natural resources management.

Egenti [15] identifies some of the objectives and functions of participation which include making local wishes known, generating development ideas, providing local knowledge and testing proposals for feasibility and improving them. Others are increasing the capability of communities to handle their affairs and to control and exploit their environments, demonstrating support for regime, doing what is required of government to be done, extracting, developing and investing in local resources (labour, finance, and managerial skills among others) and promoting desirable relationships between people, especially through cooperative work. Participation is about change that is effective, authentic and enduring and is the kind of change that is talked about when nodding towards notions like sustainability.
Participatory leadership in development programme is therefore an obvious strategy for programme success, as it is a powerful tool for mobilizing new and additional resources within the organization [16]. Social integration and social cohesion are difficult terms to define. The terms can be defined as social integration as the process that lead to social cohesion. It is undoubtedly define social cohesion as the belief held by citizens of a given nation-state that they share a moral community, which enables them to trust each other [2]. This definition brings us a bit closer to a common understanding. But despite the focus on social cohesion, it is often the absence of social cohesion that is central to the discussion. The very discussion of social cohesion often implies its absence and, even more specifically, the decline of social cohesion. The participatory leadership could take roots from earlier Amercian scholar Margaret J. Wheatley who posited a famous philosophy saying "There is no power for change greater than a community discovering what it cares about." On the other hand Helen Adams Keller posited a famous philosophy saying "Alone, we can do so little; together, we can do so much".

Despite widely recognized roles of leadership in the course transforming lives, less remains to be brought into the light on the imperative of participatory leadership on nation building towards inclusive growth in Zanzibar. It has been widely observed from many literatures that participatory leadership has been the useful tool in numerous community development programmes despite of many hindrances such as financial constraint, nonchalant attitude to maintenance, marginalization of communities due to decentralisation, abandoned project, poor mobilization, poor planning and maintenance among others. However, it has been observed from many studies that community development programmes have not been given priority by the government and citizens in many communities in Zanzibar and many other developing countries $[7,11,17,18]$. This among other things poses a rationale for revealing the imperative of participatory leadership which has high level of community involvement in all nation building processes towards inclusive growth in Zanzibar where a critical review of modern practices towards building social cohesion was undertaken in the Urban West Region, Zanzibar.

This study was attempted to specifically reveal the answers for the following three specific research objectives namely:

I. To examine the available participatory leadership practices in Zanzibar.

II. To assess the impact of participatory leadership on building social cohesion in Zanzibar.

III. To examine the factors influencing the participatory leadership practices in Zanzibar.

\section{Research Methodology}

The study was conducted in the selected shehias in Urban West Region, Zanzibar. Following various participatory leadership practices in Unguja, Zanzibar, the selected area was sought suitable for the study since it is the place where various participatory 
leadership practices have been taking place such that including community mobilization activities recently, sports and games activities have been useful applicable practices which bring people together and ensure common agenda is shared among every socioeconomic parameter in Zanzibar in the course of revealing the imperative of participatory leadership on nation building towards inclusive growth in Zanzibar. Both desk-based literature survey and descriptive survey research design were adopted for this study. The multi-stage sampling procedures were adopted for this study. Under this design both quantitative and qualitative approaches were applied to explore a real-life, contemporary bounded system or a case(s) over time, through detailed, in-depth data collection involving multiple sources of information in relation to the imperative of participatory leadership on nation building towards inclusive growth in Zanzibar in the study area [19].

The chosen study design is advantageous as it was compatible to the nature of the study on hand, available time and resources. The designated sample size of the study was 60 respondents who were treated as the total sample size. In the course of obtaining the reliable scientifically justifiable number of respondents to participate in this study as well as attaining heterogeneity of the views, the sample size determination formula adopted from Bartlett et al. [20] was employed to yield the reasonable number of respondents to participate in this present study. The study sample size of 60 respondents was envisaged to yield data and all variables of interest for the study. These respondents were selected randomly in order to get their views. Study used the sample size comprised of both male and female respondents being picked from two clusters namely Community Development Officers and Randomly sampled Citizens in Urban West Region in Zanzibar. For the purpose of this study, a sampling intensity of 5\% was adopted as presented in the Table 1 below.

Table 1: Sample size Distribution.

\begin{tabular}{|c|c|c|}
\hline Department & $\mathbf{5 \%}$ of the total employees & Total \\
\hline $\begin{array}{c}\text { Community Development } \\
\text { Officers }\end{array}$ & But not less than 30 & 30 \\
\hline $\begin{array}{c}\text { Randomly sampled } \\
\text { Citizens }\end{array}$ & But not less than 30 & 30 \\
\hline Total & & $\mathbf{6 0}$ \\
\hline
\end{tabular}

Source: Researcher, (2019).

\section{Types of data used in this study}

Both qualitative and quantitative approaches were employed in this study for the purpose of having detailed information and ensuring triangulation and complementarily. Both primary and secondary data sources were used as described below.

\section{Primary data}

The study employed primary data where diverse data collection techniques were employed study including questionnaires and interviews. Primary data were collected through self-administered and researcher assisted open and closed questionnaires. The questionnaires were carefully structured to facilitate maximum response. Questionnaires were used to enable the collection of information in a relatively short time without strict supervision of the researcher. The questionnaire method was employed to gather data from all of 60 study respondents and interviews for designated respondents from the study area.

\section{Secondary data}

In the course of supplementing the primary data, this study utilized secondary data in the course of revealing the imperative of participatory leadership on nation building towards inclusive growth in Zanzibar. Secondary data were collected through the review previous studies and documented sources like scholarly journals, thesis, books, documents and reports from various sources.

\section{Data analysis}

The study processed the collected data by the aid of Microsoft Excel and Statistical Package for Service Solutions (SPSS 20.0) computer programs. Both content analysis and descriptive and statistical analyses were employed to reveal the aspects relating to the imperative of participatory leadership on nation building towards inclusive growth in Zanzibar in the study area. Analysis of data used both quantitative and qualitative data analysis approaches including simple percentages, descriptive analysis and explanations to establish relationships of the variables employed in the study. Data analysis for each objective was rigorously performed, presented and discussed in subsequent sections hereunder.

\section{Results}

The study findings were presented in this section followed by their respective discussions in the subsequent sections.

\section{Socio-economic characteristics of respondents}

Relevant respondents' characteristics were revealed and presented in the following Table 2 below.

Table 2: Characteristics of respondents $(n=60)$.

\begin{tabular}{|c|c|c|}
\hline \multicolumn{2}{|c|}{ Characteristics Sex of respondents } & Percent (\%) \\
\hline Males & 45 & 75 \\
\hline Females & 15 & 25 \\
\hline \multicolumn{2}{|c|}{ Age of respondents } \\
\hline 18-29 years & 24 & 40 \\
\hline 30-49 years & 30 & 50 \\
\hline 50-60 years & 6 & 10 \\
\hline \multicolumn{2}{|c|}{ Education level of respondents } \\
\hline Secondary education & 11 & 40 \\
\hline Diploma Education & 24 & 41.7 \\
\hline Tertiary Education & 25 & 15 \\
\hline \multicolumn{2}{|c|}{ Experience in the study area } \\
\hline 1-10 years & 9 & 60 \\
\hline 11-20 years & 15 & 50 \\
\hline 21-30 years & 36 & \\
\hline Positions held by respondents & 30 & \\
\hline \multicolumn{2}{|c|}{ Randomly sampled Citizens } & \\
\hline
\end{tabular}

Source: Field data (2019). 
The available participatory leadership practices in Zanzibar

The study sought to reveal the available participatory leadership practices in Zanzibar in these modern times such that only seven (7) practices were revealed by the respondents who were involved in this study. The revealed findings were presented in the Table 3 below in respect with their responses rates including actual number of respondents and their respective frequencies.

Table 3: The available participatory leadership practices in Zanzibar $(n=60)$.

\begin{tabular}{|c|c|c|}
\hline Participatory Leadership Practices & Frequency & Percent (\%) \\
\hline Community Motivation and Encouragement Practices & 15 & 25 \\
\hline Community Participatory Planning & 11 & 18.3 \\
\hline Community Participatory Resource Mobilization & 9 & 15 \\
\hline Community Participatory Project Implementation & 8 & 13.3 \\
\hline Community Mobilization Practices & 7 & 11.6 \\
\hline Enhanced Community Participation and Involvement & 6 & 10 \\
\hline Community Assurance of Peace and Harmony & 4 & 6.6 \\
\hline
\end{tabular}

Source: Field data (2019).

Contribution of participatory leadership on building social cohesion in Zanzibar

This further revealed the impact of participatory leadership on building social cohesion in Zanzibar such that the employed pool of respondents by this study revealed 5 basic contributions of participatory leadership on building social cohesion in the Zanzibar community. The findings are summarized in the following Figure 1 below.

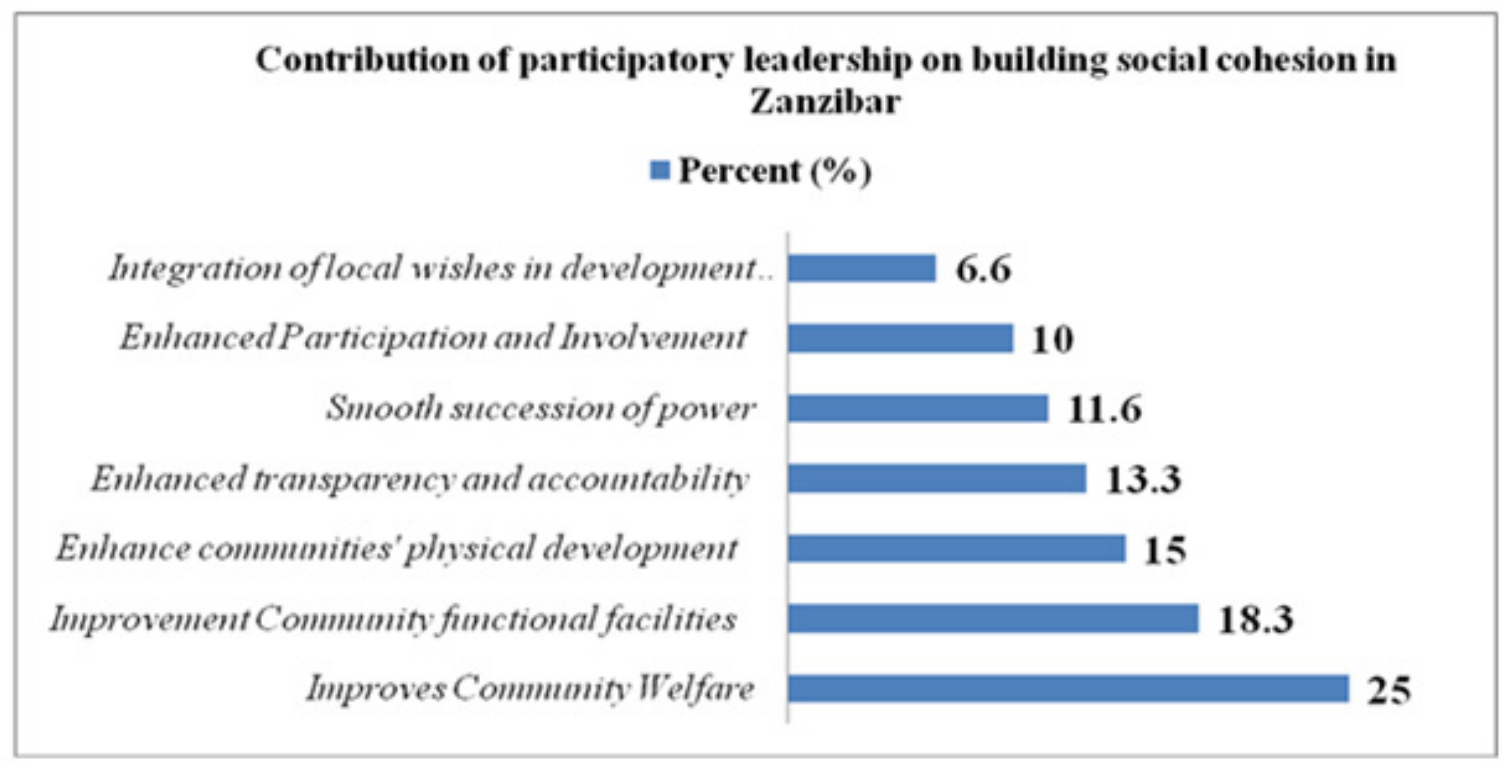

Figure 1:

Source: Field data (2019).

\section{Factors influencing the participatory leadership practices in Zanzibar}

In the course of bringing the real factors influencing the participatory leadership practices in the basic Zanzibar context into understanding, firstly the study sought to reveal the potential actors in the participatory leadership process in Zanzibar. The revealed actors were sought relevant to be brought into knowledge since they are useful in implementing participatory leadership practices in various levels and stages of community development in Zanzibar.

On the other hand the study revealed the factors influencing the participatory leadership practices in Zanzibar. The factors influencing the participatory leadership practices in Zanzibar were revealed and hereby summarized in the Table 4 below. The YES and NO questions were addressed in the course of looking for most suitable factors which influence the participatory leadership practices in Zanzibar (Figure 2). 


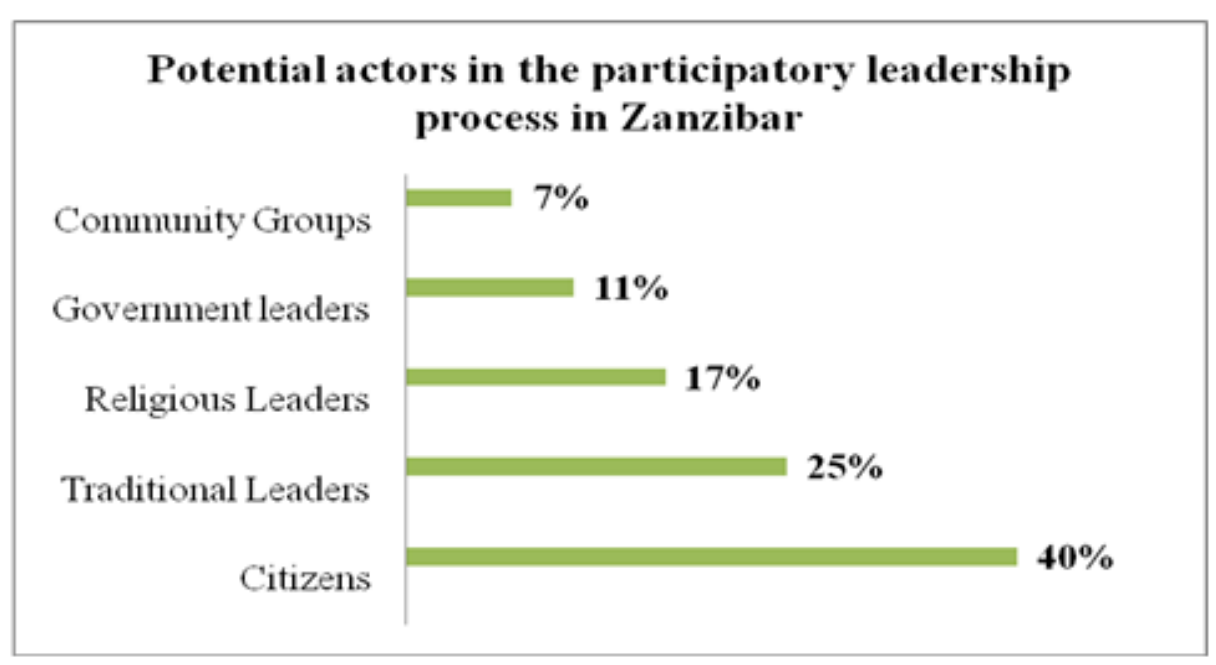

Figure 2:

Source: Field data (2019).

Table 4: Factors influencing the participatory leadership practices in Zanzibar $(n=60)$.

\begin{tabular}{|c|c|c|c|c|}
\hline \multirow{2}{*}{ Factors } & \multicolumn{4}{|c|}{ Responses (\%) } \\
\cline { 2 - 5 } & \multicolumn{2}{|c|}{ YES } & \multicolumn{2}{c|}{ NO } \\
\cline { 2 - 5 } & $\mathbf{n}$ & $\mathbf{\%}$ & $\mathbf{n}$ & $\mathbf{\%}$ \\
\hline Community attitudes & 55 & 92 & 5 & 8 \\
\hline Community Average Education level & 50 & 83 & 10 & 17 \\
\hline Strength of Community Relationships & 45 & 75 & 15 & 25 \\
\hline Strength of Community Networks & 48 & 80 & 12 & 20 \\
\hline Resources Mobilization Skills & 45 & 75 & 15 & 25 \\
\hline Understanding of the role of agenda & 55 & 92 & 5 & 8 \\
\hline Supportive Legal Provisions & 50 & 83 & 10 & 17 \\
\hline Supportive Policies, Strategies and & 46 & 77 & 14 & 23 \\
\hline Programmes & 42 & 70 & 18 & 30 \\
\hline Leadership legitimacy and affection & & & & \\
\hline
\end{tabular}

Source: Field data (2019).

\section{Discussions}

\section{Socio-economic characteristics of respondents}

Respondents' characteristics were important in order to provide a snapshot on the background of the respondents and their suitability for this study. It was sought of essence to underscore the useful and relevant socio-economic characteristics 60 respondents who participated in this study. The respondents were randomly drawn from the selected from the useful community segments, departments and units in the study area, however the selection of the mentioned departments and units was purposively done to fit statistical analyses hence meeting a total of 60 people. Among all respondents $50 \%$ were community development officers while $50 \%$ were randomly sampled citizens. This mixture of respondents contained potential respondents for providing relevant responses in relation to questions under study. Other relevant characteristics of the 60 respondents who took part in this study include age, sex, education and experience in the study area. The characteristics were summarized and presented in the Table 2.

From the study results, the presence of $75 \%$ and $25 \%$ of all respondents of males and female respectively reflect the patriarchy image in the participation aspect for majority of communities in Zanzibar such that males are the most active segment of community followed by women. In the randomly selection of respondents, male respondents appeared to be more than female respondents.

On the other hand the study findings revealed majority (50\%) of respondents were of 30-49 years hence positing them as the most active group of members of the society. Similarly, on the education level of the entire pool of respondents, the study findings revealed that majority $(81.7 \%)$ of the study respondents had acquired diploma education and above. This implied the participation of the learned pool of respondents in the study area. Lastly, the study findings revealed respondents' experience in the study area as the useful parameter which could easily define the level of fitness of the respondents under questions such that majority $(60 \%)$ of respondents has spent 21-30 years in the study area experiencing all aspects and practices under study. These study findings further concur with various viewpoints from URT, Akinyemi \& Otite [11] such that the said population with majority of respondents under study entails a working age population hence the study respondents were the proper group of the business community. Corroborating this view, a World Bank report (1995) cited in Ugwu [14] study finding suggesting the availability of supportive workforce for effective and sustainable adaptation and adoption of sustainable development practice.

\section{The revealed participatory leadership practices in Zanzibar}

In the course of revealing the available participatory leadership practices in Zanzibar, only seven (7) practices were revealed as 
presented in Table 3 above. The revealed findingsincludeCommunity Motivation and Encouragement Practices (25\%), Community Participatory Planning (18.3\%), Community Participatory Resource Mobilization (15\%), Community Participatory Project Implementation (13.3\%), Community Mobilization Practices (11.6\%), Enhanced Community Participation and Involvement practices (10\%) and Community Assurance of Peace and Harmony $(6.6 \%)$.

The revealed available participatory leadership practices in Zanzibar, mainly in the Urban West Region have been useful in innovating new community development interventions as a matter of fact that the practices are useful in mobilizing and integrating people in the course of contributingmeaningfully to the development process. The study findings imply that participatory leadership as the key element in the process of national development in general hence reflecting views from numerous study findings including [1-3]. The revealed participatory leadership practices were widely reported to be useful influencing community development initiatives.

The existence of participatory leadership practices in the Urban West Region occurs in various forms including formal community meetings, sports and games events, and information sharing systems which are quite useful in organizing many communities to commit themselves with initiatives to embark on activities that could transform their local and rural environment into urban and better developed settings. It is through the existence of these practices that concurred the findings from Mahmoud [2] that the recently adopted means of employing communal efforts as the mechanism for mobilizing community resources for development activities calls for participatory leadership in maintaining that sphere. The existence of practices including community motivation and encouragement such regular meetings, sports and games events enable strong information sharing platform which facilitate community participatory planning and consequently result to community participatory resource mobilization hence improve various aspects of their life of the particular community.

\section{Revealed contribution of participatory leadership on building social cohesion in Zanzibar}

The study findings envisaged the participatory leadership practices role on improving community welfare $(25 \%)$ such that the community could fulfill her own needs in the presence of participatory leadership in the area due to the fact that the leadership system in the question has high level of openness, transparency and commitment in the course of bringing local community's wishes in the implementation. On the other hand the study findings revealed substantial contribution namely improving community functional facilities (18.3\%) also enhanced transparency and accountability $(13.3 \%)$ such that other revealed contributions include enhanced participation and involvement (10\%), smooth succession of power $(11.6 \%)$ and integration of local wishes in development ideas $(6.6 \%)$.
It is matter of fact that participatory leadership has a significant contribution in the course of building social cohesion in various communities in Zanzibar. Basing on the widen participation and involvement of community in the leadership process hence managing to bring majority of community members on board, hence making development process more sustainable. The study findings are summarized in the following Figure 1 above reflect the arguments from Mahmoud [2] \& Abiona [3] that identified some key elements of programmes sustainability along participatory leadership including nature of programme should be people oriented, the need for stability of government and stable policies; transparency and accountability in all sectors; equal access to resources; and effective political system; recognition and involvement of local institutions in development programmes. The study findings revealed the direct relationship between participatory leadership and sustainability of community development initiatives in many areas including Zanzibar, mainly in the Urban West Region where participatory leadership practices are widely conducted.

\section{Revealed factors influencing the participatory leadership practices in Zanzibar}

The fact that participatory leadership practices have been practiced in the area by a wider pool of actors namely Citizens (40\%), Traditional Leaders (25\%), Religious Leaders (17\%), Government leaders (11\%) and Community Groups (7\%). The study findings managed to map out the potential actors who could have been useful in organizing and implementing participatory development initiatives in the spirit of participatory leadership. Since the government leaders always seem to carry the wishes of the entire community towards any development intervention, the study findings revealed citizens as the main agent in the entire participatory process. The findings on the potential actors reflect and appreciate the rationale and significance of participatory leadership hence undergoes a very rapid transformation from mere provision of rudimentary tasks to a more complex task of supplementing governments' efforts in the provision of basic and social services. Hence the revealed actors concur from the Mahmoud [2], Akinyemi [7] \& Abiona [3] such that, government needs to integrates more actors for the sustainable development process.

On the other hand the study revealed the factors influencing the participatory leadership practices in the Urban West, Zanzibar. Basing on the study findings presented in the Table 4, community attitudes was highly responded by the majority of the engaged study respondents (92\%) such that mentality of the members of the particular community have to be integrated in the entire process of thinking, designing and implementing participatory leadership practices. This study finding is supported by the findings from Akinyemi and Otite [11] which portray the usefulness of community attitudes in the course of enhancing the effectiveness of community development programmes such as lukewarm attitude to maintenance, exodus of people from rural to urban area, wrong belief of people that government was capable and should 
provide all their needs for them, inadequate funding on the part of individual members, problem of illiteracy and communal clashes among others. However, the study findings point out another critical factor namely level of understanding of the role of agenda among the members of the community where majority (92\%) of respondents concurred. Among other revealed factors as presented in the Table 4 above include community average education level, strength of community relationships, strength of community networks, resources mobilization skills, supportive legal provisions, supportive policies, strategies and programmes and leadership legitimacy and affection.

The revealed factors influencing the participatory leadership practices in Zanzibar reflect the findings from Obanigwe, Abiodun and Maureen [13] such that the government efforts to achieve meaningful development at the grassroots, despite the widely known usefulness of participatory leadership still many communities are still in pathetic state of stagnation and neglect. The backwardness and lack of progress in many of the government sponsored projects roots from the direct or indirect cause of the revealed factors influencing the participatory leadership practices. However, many community projects were abandoned half-way due to poor logistics and financial constraint, poor planning and management. Indeed, participatory leadership has failed in many areas in the world due to the revealed factors. The recently, invitation and integration of participatory leadership practices community supported projects, the number of beggars along the Zanzibar streets has decreased drastically and other practically evidenced improvements into other social and economic development initiatives in Zanzibar.

\section{Conclusion}

This study sought to reveal the imperative of participatory leadership towards inclusive growth in Zanzibar where a critical review of modern practices towards building social cohesion was undertaken in the Urban West Region, Zanzibar. This study concludes community motivation and encouragement practices, community participatory planning, community participatory resource mobilization, community participatory project implementation, community mobilization practices, enhanced community participation and involvement practices and community assurance of peace and harmony as the main available participatory leadership practices in Zanzibar.

On the other hand, it was concluded from the study findings, that the contribution of participatory leadership on building social cohesion in Zanzibar include improving community welfare, improving community functional facilities and also participatory leadership enhances transparency and accountability among various actors in the community. Finally, the study concludes citizens, traditional leaders, religious leaders, government leaders and community groups as the main actors in the participatory leadership practices undertaken in the Urban West Region, Zanzibar. Lastly basing on the study findings, community attitudes were concluded to be the major factor among the revealed factors influencing the participatory leadership practices in the Urban West, Zanzibar.

\section{Recommendations}

Based on the study findings, the following recommendations have been put forward to the respective actors:-

Firstly, the government leaders are urged to deliberately change their leadership style such that involve and engage wider part of the community members as it has been proven to be highly useful.

Secondly, the traditional and religious leaders are hereby urged by this study to equip themselves with the basic understanding of the participatory leadership. This will be a useful strategy for joining hands with government leaders in quick and effective community mobilization process.

Finally, the citizens who stand as one of the potential actors in the participatory leadership process should cultivate the culture and mentality for fitting them in the participatory leadership process such that their attitudes can start changing to adapt and fit the participatory leadership practices. Lastly, the study urges government authorities mainly the authorities which regulate education sector to prepare the curriculum for building-up the culture in schools and other formal and informal learning institutions in Zanzibar. This will ensure the change in attitudes and behaviors towards adoption of participatory leadership practices in their daily participation in the development initiatives.

\section{References}

1. Onabanjo FA (2004) Community Development: Rural Development and Planned Social Change. Felix Enterprises, Lagos, Nigeria, pp. 1-44.

2. Mahmoud AM (2019) The role of voluntary patriotic practices on poverty reduction initiatives in Zanzibar: A case of West B District in Urban West Region, Zanzibar. Unpublished Master Thesis from Open University of Tanzania, Tanzania.

3. Abiona IA (2009) Principles and Practice of Community Development. Ibadan University Press, Nigeria, pp. 17-81.

4. Mahmoud, Ayoub M (2018) Contribution of Voluntary Patriotic Practices on Poverty Reduction Initiatives in Zanzibar. Journal of Current Investigations in Agriculture and Current Research. 5(5).

5. RGZ (2010) The Zanzibar Strategy for Growth and Reduction of Poverty: 2010-2015 (ZSGRP II): MKUZA II. Zanzibar, Tanzania, pp. 197.

6. Adegboye MA (2005) Sources of Motivation to Rural Dwellers Participation in Self-help Projects in Plateau States, Nigeria. Ph.D Thesis Department of Agricultural Extention and Rural Development, University of Ibadan, Ibadan, Nigeria.

7. Akinyemi VI (1994) Determinants of Citizen Participation in Community Development Activities in Ondo state. Ph.D Thesis, Department of Adult Education, University of Ibadan, Nigeria.

8. MKUZA (2012) Zanzibar strategy for growth and reduction of poverty (ZSGRP II) The Revolutionary Government of Zanzibar. Publication.

9. Anyanwu CN (1981) Principles and Practice of Adult Education and Community Development. Abiprint Publishing Company Limited, Ibadan, Nigeria, pp. 189-194.

10. Abu PB, Oghenekohwo JE (2003) Citizens Participation in Community Development in Developing Countries. International Journal of Continue and Non-Formal Education 2(1): 63.

11. Otite RE (2002) Partnering in Community Development: A Study of Three Rural Communities in Delta State Nigeria. Thesis Department of Adult Education, University of Ibadan, Ibadan, Nigeria, p. 114. 
12. Oyelami RO (2007) Community Participation and Performance in Secondary Schools in Oyo and Osun States, Nigeria. Unpublished Ph.d Thesis university of Ibadan, Nigeria.

13. Maureen NE (2005) Appraisal of the Due Process in The Principles, Methods and Techniques of Managing Community Development Projects for Development in Adult and Non-Formal Education in Nigeria: Ibadan Emerging Issues, papers from the NNCAE Annual Conference. p.16.

14. Ugwu SC (2000) Issues in local government and urban administration in Nigeria. Enugu Academic Printing Press.

15. Egenti MN (2001) The influence of citizen participation in self - help projects on the welfare of people in Imo state, Nigeria. University of Ibadan, Nigeria.

16. Anyanwu CN (1992) Community Development: The Nigerian Perspective. Gabesther Educational Publishers, Ibadan, Nigeria, p. 348.
17. Adedokun OM (1998) The Contributions of Community Education to Sustainable Community Development Project in Oyo state, (19871996). Ph.D thesis Department of Adult Education, University of Ibadan, Ibadan, Nigeria.

18. Akoroda O (2012) Citizen Participation in Self-Help Projects and Socio- Economic Development in Communities in Delta and Oyo States. University of Ibadan, Nigeria.

19. Babbie ER (2007) The Basics of Social Research. $4^{\text {th }}$ (edn), Thomson Wadsworh, USA, pp. 576.

20. Bartlett EJ, Kotrlick WJ, Haggins CC (2001) Organizational research: Determining appropriate sample size in survey research. Information Technology, Learning and Performance 19(1): 43-50.

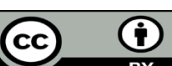

This work is licensed under Creative Commons Attribution 4.0 License

To Submit Your Article Click Here: Submit Article

DOI: 10.32474/TCEIA.2019.03.000168

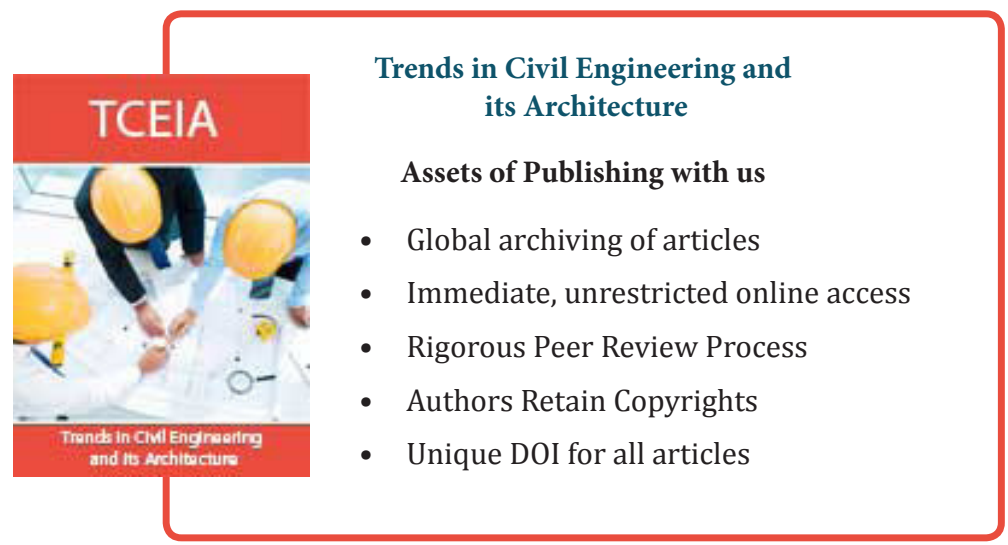

